\title{
PEMBERDAYAAN KELUARGA DALAM PENGONTROLAN TEKANAN DARAH PASIEN HIPERTENSI PADA MASA PANDEMIK COVID-19 DI PUSKESMAS LIMO DEPOK
}

\author{
Mila Citrawati $^{1}$, Citra Ayu Aprilia ${ }^{2}$, Yanti Harjono ${ }^{3}$ dan Diana Agustini ${ }^{4}$ \\ ${ }^{1}$ Fakultas Kedokteran, UPN Veteran Jakarta \\ Surel: milacitrawati@upnvj.ac.id \\ ${ }^{2}$ Fakultas Kedokteran, UPN Veteran Jakarta \\ Surel: citra.ayuaprilia@upnvj.ac.id \\ ${ }^{3}$ Yanti Harjono, UPN Veteran Jakarta \\ Surel: yantiharjono@upnvj.ac.id \\ ${ }^{4}$ Fakultas Kedokteran, UPN Veteran Jakarta \\ Surel: dianaagustini@upnvj.ac.id
}

\begin{abstract}
The definition of hypertension or high blood pressure is a condition when blood pressure reaches a value of $\geq 140 / 90$ mmHg. If not treated immediately, hypertension can cause serious life-threatening diseases, such as heart failure, kidney disease, and stroke. During the Covid-19 pandemic which has been going on since the beginning of 2020, most government health facilities have become centers for handling Covid 19 patients. So it is difficult for patients other than Covid 19 to come for treatment. Depok has a fairly high number of hypertensive patients and is currently having problems with regular check-ups at the puskesmas. This can make it difficult to control the condition of hypertension patients, apart from the puskesmas being the first service center for Covid-19 patients, the risk of contracting Covid19 is also high if the patient comes to the puskesmas for control. Various studies on family empowerment in treating hypertensive patients have become one of the basics for our community service team to educate respondents who have family members with hypertension. This community service activity aims to increase knowledge about hypertension and how to control it in respondents so that family empowerment in treating hypertension patients can be improved. To determine the level of understanding of respondents on educational materials, questionnaires were filled out before and after education. The results achieved in this activity is an increase in respondents' knowledge about hypertension and how to control it with family participation.
\end{abstract}

Keywords: hypertension, education, family empowerment

\begin{abstract}
ABSTRAK
Hipertensi (tekanan darah tinggi) adalah kondisi tekanan darah mencapai nilai $\geq 140 / 90 \mathrm{mmHg}$. Hipertensi dapat mengakibatkan beberapa penyakit yang mengancam nyawa, seperti gagal jantung, penyakit ginjal, dan stroke, jika tidak segera ditangani. Pandemi Covid-19 yang sudah berlangsung sejak awal tahun 2020 memaksa sebagian besar fasilitas kesehatan milik pemerintah menjadi pusat penanganan pasien Covid-19. Sehingga menjadi masalah bagi pasien selain Covid-19 untuk datang berobat. Depok memiliki angka pasien hipertensi yang cukup tinggi dan saat ini terkendala untuk kontrol rutin ke puskesmas. Hal ini dapat mengakibatkan sulitnya mengontrol kondisi pasien hipertensi selain puskesmas menjadi pusat layanan pertama untuk pasien Covid-19, risiko tertular Covid-19 juga tinggi apabila pasien datang ke puskesmas untuk kontrol. Berbagai penelitian mengenai pemberdayaan keluarga dalam merawat pasien hipertensi menjadi salah satu dasar tim pengabdi untuk melakukan edukasi kepada responden yang mempunyai anggota keluarga penderita hipertensi. Kegiatan pengabdian kepada masyarakat ini mempunyai tujuan meningkatkan pengetahuan tentang penyakit hipertensi dan cara mengendalikannya pada responden sehingga pemberdayaan keluarga dalam merawat pasien hipertensi dapat ditingkatkan. Untuk mengetahui tingkat pemahaman responden atas materi edukasi dilakukan pengisian kuesioner sebelum dan sesudah edukasi. Hasil yang dicapai pada kegiatan ini adalah peningkatan pengetahuan responden tentang penyakit hipertensi dan cara pengendaliannya dengan peran serta keluarga.
\end{abstract}

Kata Kunci: hipertensi, edukasi, pemberdayaan keluarga

\section{PENDAHULUAN}

Hipertensi dikenal sebagai salah satu penyakit yang bersifat kronis dan silent killer. Prevalensi penyakit hipertensi sangat tinggi khususnya pada lansia. Menurut Guidice dalam Zulfitri, diperkirakan 60\%-80\% dari lansia > 60 tahun menderita hipertensi (Zulfitri, 2019). Berdasarkan 
Riskesdas 2018 dapat dilihat bahwa terjadi peningkatan kejadian hipertensi dibandingkan hasil Riskesdas 2013. Hasil ini berdasarkan hasil pengukuran tekanan darah pada masyarakat yang berusia 18 tahun ke atas (Badan Penelitian dan Pengembangan Kesehatan, 2019). Menurut Riskesdas 2018, prevalensi hipertensi di Kota Depok adalah sebesar 34.13\%. Berdasarkan hal tersebut dapat menunjukkan bahwa intervensi untuk penurunan angka kejadian hipertensi masih dibutuhkan khususnya pada Puskesmas kecamatan Limo (Kementerian Kesehatan RI, 2019).

Menurut WHO pada saat pandemi fasilitas kesehatan terpusat menangani lonjakan pasien Covid19 sehingga layanan kesehatan bagi masyarakat dengan penyakit selain Covid 19 mengalami hambatan. Hal tersebut dapat dilihat pada 53\% dari 155 yang dilakukan survei tersebut menyatakan akses layanan kesehatan untuk pengobatan hipertensi tertunda. Penyakit hipertensi sendiri merupakan salah satu faktor komorbid yang dapat memperberat penyakit Covid-19. Berdasarkan hal tersebut maka penyakit hipertensi merupakan salah penyakit yang menjadi perhatian di masa pandemi ini (Susanti, 2021).

Penguatan kesehatan keluarga dengan cara meningkatkan peran serta keluarga dalam perawatan kesehatan anggota keluarga yang menderita penyakit dilakukan dengan memperhatikan beberapa faktor. Faktor-faktor yang harus diperhatikan antara lain adalah memahami masalah kesehatan anggota keluarganya, mempunyai kemampuan memutuskan tindakan yang harus dilakukan, merawat setiap anggota keluarga yang memiliki masalah kesehatan, mengusahakan lingkungan yang menunjang kesehatan dan mampu menggunakan fasilitas kesehatan. Kelima faktor tersebut adalah yang dapat menentukan apakah keluarga dapat berperan serta mengatasi masalah kesehatan anggota keluarganya (Friedman, 2010).

Perawatan anggota keluarga yang menderita hipertensi sangat bergantung pada peran anggota keluarga lainnya. Keluarga harus memiliki pengetahuan yang cukup tentang hipertensi dan komplikasinya. Pengetahuan tersebut antara lain, adalah; keteraturan minum obat antihipertensi untuk mencegah komplikasi, nutrisi yang sehat, dan gaya hidup yang sesuai untuk pasien hipertensi. Maka implementasi dari pengetahuan tersebut, anggota keluarga ini akan berperan mengingatkan pasien untuk minum obat teratur, menyediakan makanan yang sesuai kondisi pasien dan memperhatikan gaya hidup pasien (olahraga teratur, tidak mengonsumsi alkohol dan tidak merokok, serta menghindari stress) (Masumeh, 2018; Marlina, 2019).

Upaya meningkatkan kemampuan keluarga untuk memberikan dukungan dalam mengontrol tekanan darah pada penderita hipertensi dengan meningkatkan pengetahuan adalah merupakan suatu bentuk pemberdayaan keluarga. Pemberdayaan keluarga dapat mempengaruhi gaya hidup penderita hipertensi sehingga dapat menurunkan progresifitas hipertensi. Keluarga menjadi sistem penunjang dalam kehidupan pasien hipertensi, agar keadaan yang dialami tidak semakin memburuk dan terhindar dari komplikasi (Zulfitri et al., 2019).

Beberapa hasil penelitian menunjukkan bahwa perilaku sehat penderita hipertensi dikontrol oleh peran keluarga. Selain itu juga menunjukkan bahwa terdapat hubungan antara peran keluarga sebagai pendukung kondisi kesehatan, yang teridir dari durasi dan derajat penyakit, kematian, pengendalian kontrol tekanan darah, kesehatan psikologis, perilaku sehat, kepatuhan lansia dalam menjaga dan mematuhi segala yang dianjurkan oleh tenaga kesehatan (Hariawan \& Tatisina, 2020).

Permasalahan yang dihadapi mitra adalah pada saat pandemi Covid-19 ini adalah pasien hipertensi diharapkan agar tetap terkontrol penyakitnya dengan tetap rutin kontrol ke fasilitas kesehatan. Namun di sisi lain pasien hipertensi terutama lansia mengalami kesulitan melakukan hal tersebut mengingat puskesmas adalah termasuk tempat yang berisiko untuk terjangkitnya Covid-19. Berdasarkan permasalahan tersebut, tim pengabdian bertujuan meningkatkan pengetahuan tentang penyakit hipertensi pada keluarga pasien sehingga mereka dapat berperan serta dalam merawat dan mengontrol tekanan darah pasien. 


\section{METODE PELAKSANAAN PKM}

Pelaksanaan kegiatan pengabdian kepada masyarakat ini dilakukan dengan metode ceramah (penyuluhan) tentang penyakit hipertensi dan komplikasinya terhadap responden yang mempunyai anggota keluarga dengan penyakit hipertensi. Selain itu juga edukasi tentang peran serta keluarga untuk merawat anggota keluarga yang menderita hipertensi meliputi jenis dan jadwal minum obat, nutrisi dan gaya hidup yang sesuai untuk pasien hipertensi. Ceramah dilakukan dengan cara interaktif, responden diberikan kesempatan bertanya kepada tim pengabdi tentang materi yang dipaparkan. Selain ceramah responden juga diberikan buku saku panduan tentang hipertensi.

Responden didapat dari peran aktif kader kesehatan Puskesmas Limo. Jumlah responden yang hadir 31 orang yang dibagi dalam beberapa sesi untuk menjaga protokol kesehatan. Edukasi berjalan selama 2 jam setiap sesi.

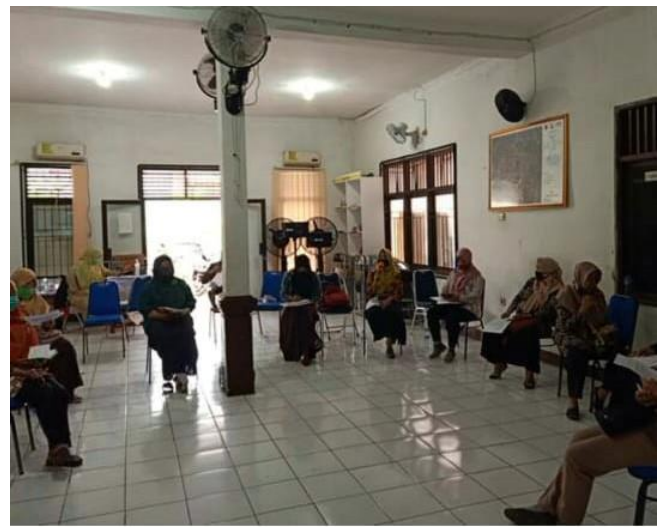

Gambar 1. Edukasi Responden

BUKU KONTROL HIPERTENSI

UNTUK PENDAMPING PASIEN

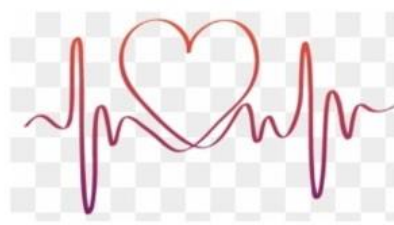

OLEH:

TMM PENGABDIAN KEPADA MASYARAKAT UNIVERSTTAS PEMBANGUNANAN NASTONAL VETERAN
$\mathrm{BAB} 1$

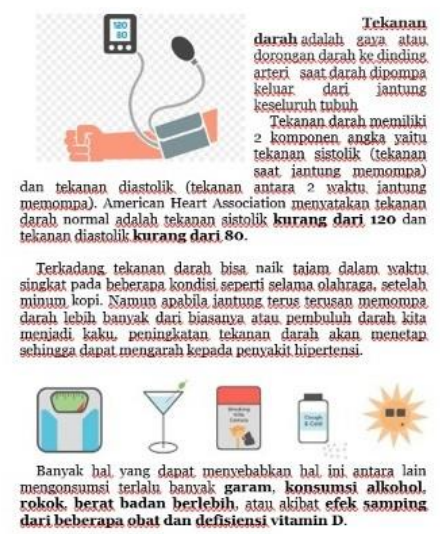

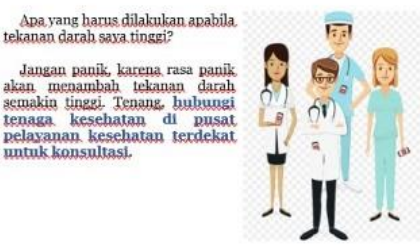

Gambar 2. Panduan Untuk Keluarga Pasien Hipertensi 

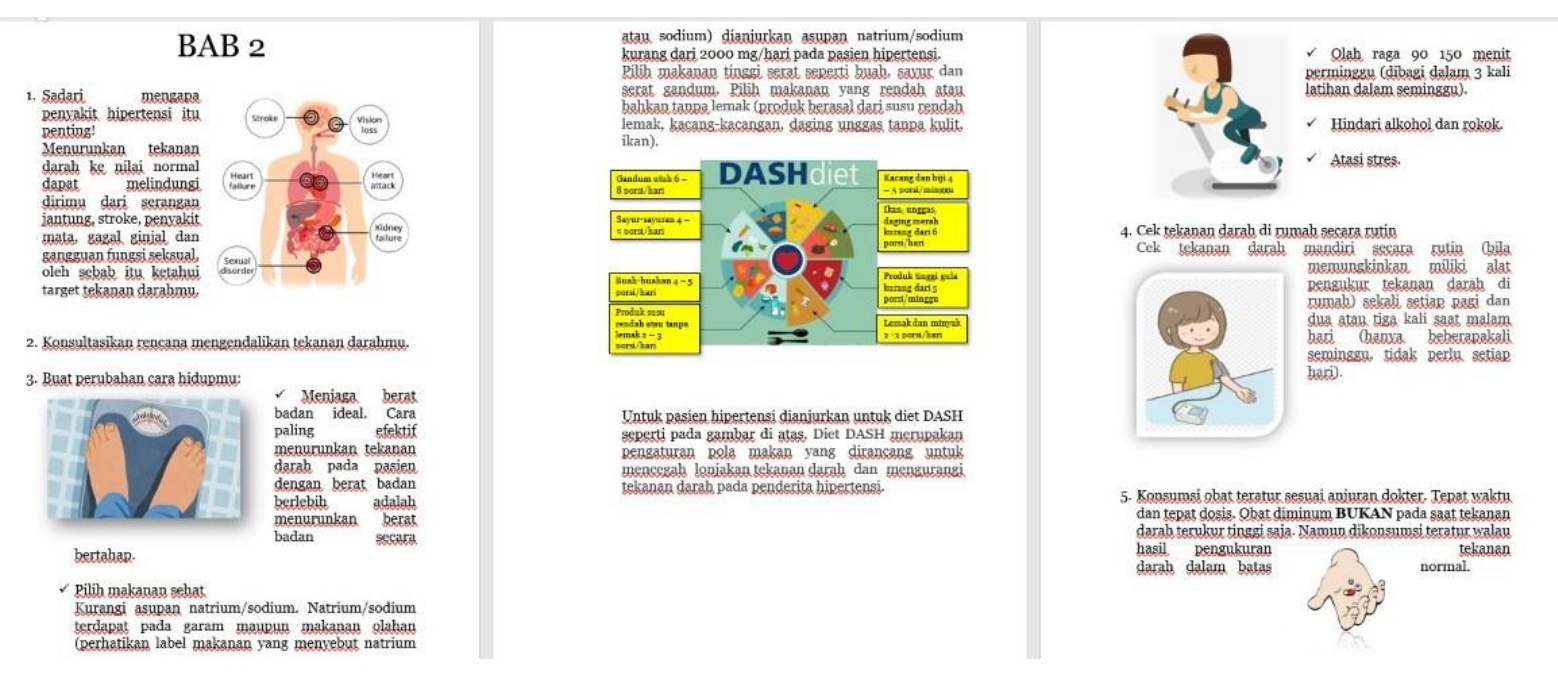

Gambar 3. Isi Buku Panduan Keluarga Pasien Hipertensi

\section{HASIL DAN PEMBAHASAN}

Hasil evaluasi, secara keseluruhan responden memahami materi penyuluhan. Sebelum edukasi dilakukan pemberian pre-test dengan hasil range nilai dari 20 sampai 80 dengan median 60 . Setelah edukasi didapatkan hasil post-test dengan range nilai 40 sampai 100 dengan median 70. Selain pre dan post-test, responden diberi kesempatan bertanya tentang materi penyuluhan. Cukup banyak pertanyaan yang diajukan tentang materi penyuluhan. Target jumlah peserta terpenuhi $90 \%$ responden dilakukan penyuluhan dan menerima materi yang dilakukan oleh tim pengabdian kepada masyarakat. Setelah dilakukan tanya jawab dapat dilihat bahwa ada peningkatan pengetahuan dari responden mengenai penyakit hipertensi dan cara mengendalikannya. Semua materi penyuluhan dapat disampaikan oleh tim pengabdian kepada masyarakat dengan waktu yang terbatas.

Pada penelitian Wahyudi tahun 2017 tentang kepatuhan minum obat pada pasien hipertensi di Limo, Depok didapatkan 35,8\% responden tidak patuh minum obat (Wahyudi, 2017). Meskipun terapi farmakologis dan non-farmakologis efektif, sekitar setengah dari pasien hipertensi tetap tidak terkendali. Dengan pengawasan oleh keluarga dalam mematuhi terapi farmakologi, hanya sekitar 40-50\% dari pasien penyakit kronis seperti hipertensi yang mematuhi pengobatan. Kepatuhan pasien terhadap terapi dapat didefinisikan sebagai berikut melalui perubahan pola makan, pengobatan, dan gaya hidup yang direkomendasikan oleh fasilitas kesehatan. Kepatuhan terapi yang buruk mencegah pasien mencapai tujuan akhir pengendalian tekanan darah. Tekanan darah yang tidak terkontrol, menyebabkan meningkatnya kunjungan ke fasilitas kesehatan, penurunan kualitas hidup pasien, dan peningkatan biaya (Masumeh, 2018).

Oleh sebab itu intervensi dengan edukasi secara interaktif terhadap keluarga untuk mempromosikan gaya hidup sehat dan pengontrolan tekanan darah pasien hipertensi dinilai efektif. Mengaktifkan peran serta keluarga dalam pengontrolan tekanan darah pasien hipertensi diharapkan dapat membantu di saat pandemi seperti ini. Sistem kesehatan dan pembuat keputusan dapat mempertimbangkan edukasi berorientasi keluarga pada menejemen pasien hipertensi. Semua hal tersebut dapat mengurangi biaya medis baik pada pasien maupun fasilitas kesehatan (Masumeh, 2018; Mahrokh, 2015). 


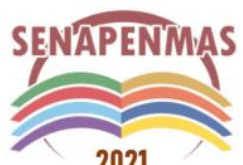

2021
Seminar Nasional Hasil Penelitian dan Pengabdian Kepada Masyarakat 2021 Pengembangan Ekonomi Bangsa Melalui Inovasi Digital Hasil Penelitian dan Pengabdian Kepada Masyarakat Jakarta, 21 Oktober 2021

\section{KESIMPULAN DAN SARAN}

Kegiatan penyuluhan peran keluarga dalam mengontrol tekanan darah pasien hipertensi di Limo Depok menambah pengetahuan responden tentang penyakit hipertensi dan cara merawat pasien hipertensi. Dengan demikian keluarga pasien hipertensi dapat berperan aktif mengawasi pasien dengan bermodalkan pengetahuan tentang penyakit hipertensi dan pengendalian tekanan darah. Oleh sebab itu, disarankan agar dilakukan edukasi berulang seperti diadakannya diskusi kelompok kecil dengan kehadiran anggota keluarga untuk mempromosikan penerapan gaya hidup yang lebih sehat dan mengelola tekanan darah lebih baik pada pasien dengan hipertensi. Hal tersebut dapat dimasukkan sebagai program kerja fasilitas kesehatan primer.

Pelaksanaan pengabdian kepada masyarakat ini tak lepas dari bantuan banyak pihak. Tim pengabdi menyampaikan ucapan terimakasih kepada Kepala Puskesmas Kecamatan Limo Depok, para kader, responden dan mahasiswa FK UPN Veteran Jakarta sebagai asisten pelaksana pengabdian. Tim pengabdi juga mengucapkan terimakasih kepada UPN Veteran Jakarta atas dana yang diberikan untuk melangsungkan pengabdian.

\section{REFERENSI}

Badan Penelitian dan Pengembangan Kesehatan. (2019). Laporan Nasional RISKESDAS 2018. Badan Penelitian dan Pengembangan Kesehatan. Retrieved from http://labdata.litbang.kemkes.go.id/images/download/laporan/RKD/2018/Laporan_Nasiona 1_RKD2018_FINAL.pdf

Friedman M M, Bowden V R and Jones E G 2010 Family Nursing: Research, Theory and Practice 7 th Edition. (New Jersey: Pearson Education Inc.)

Hariawan, H., \& Tatisina, C. M. (2020). Pelaksanaan Pemberdayaan Keluarga Dan Senam Hipertensi Sebagai Upaya Manajemen Diri Penderita Hipertensi. Jurnal Pengabdian Masyarakat Sasambo, 1(2), 75. https://doi.org/10.32807/jpms.v1i2.478

Kementerian Kesehatan RI. (2019). Laporan Provinsi Jawa Barat, Riskesdas 2018. Lembaga Penerbit Badan Penelitian dan Pengembangan Kesehatan.

Mahrokh Keshvari, Batool Hedayati, Mahin Moeini, and Fatemeh Alhani (2015). A survey on the effect of implementation of a family-centered empowerment model on blood pressure and empowerment dimensions in the elderly people with hypertension. J Educ Health Promot. 2015; 4: 94

Marlina, Badaruddin, Z Fikarwin and R Lubis (2019). Model of family health empowerment preventing stroke in Puskesmas Ulee Kareng Banda Aceh. Journal of Physics: Conference Series, 1460 (2020) 012076

Masumeh Hemmati Maslakpak, Behrooz Rezaei \& Naser Parizad | Albert Lee (Reviewing editor) (2018) Does family involvement in patient education improve hypertension management? A single-blind randomized, parallel group, controlled trial, Cogent Medicine, 5:1, DOI: 10.1080/2331205X.2018.1537063

Susanti, Y., Anita, \& Santoso, D. Y. A. (2021). Perilaku Cerdik Penderita Hipertensi di masa Pandemi COVID 19. Jurnal Keperawatan, 13, 40-46.

Wahyudi CT, Ratnawati D, Made SA (2017). Pengaruh Demografi, Psikososial Dan Lama Menderita Hipertensi Primer Terhadap Kepatuhan Minum Obat Antihipertensi. Jurnal JKFT: Universitas Muhammadiyah Tangerang Vol. 2,Juli -Desember,tahun 2017 : 14-28

Zulfitri, R., Indriati, G., Amir, Y., \& Nauli, F. A. (2019). Pemberdayaan Keluarga Sadar Hipertensi (Gadarsi) Dalam Peningkatan Gaya Hidup Sehat Penderita Hipertensi. Jurnal Ners Indonesia, 9(2), 182. https://doi.org/10.31258/jni.9.2.182-188 
Seminar Nasional Hasil Penelitian dan Pengabdian Kepada Masyarakat 2021

Pengembangan Ekonomi Bangsa Melalui Inovasi Digital Hasil Penelitian dan

Pengabdian Kepada Masyarakat

Jakarta, 21 Oktober 2021

(halaman kosong) 